\title{
The legitimacy of offender management programmes in a post-TR landscape
}

\author{
Michael Rowe, Adele Irving and Sarah Soppitt
}

\begin{abstract}
Purpose - The purpose of this paper is to explore the under-considered perspectives of service users engaged in various community sentences based on a "strengths-based" approach to desistance. Further to recent changes in the sector, the paper considers service user views for programmes delivered by combinations of agencies from private, public and third sectors.

Design/methodology/approach - The paper is based on analysis of 64 semi-structured interviews with users of four programmes, accompanied with informal fieldwork observations by the researchers as they carried out the research at the premises of service providers.

Findings - The research finds that service user perceptions of the legitimacy of programmes are closely related to their understanding of three key dimensions: first, the "authenticity" of those delivering the service; second, the instrumental (in broad terms) gains they expect from engagement; and third, their understanding of the identity and ethos of the programme.

Originality/value - The paper adds important understanding based on service user perceptions in a period when service provision is being diversified. Further directions for other research are identified and it is recognised that a limitation of the current study is that it incorporates a sample drawn from one area.
\end{abstract}

Keywords Legitimacy, Offender perspectives, Probation, Transforming Rehabilitation,

Community sentences, Offender narratives

Paper type Research paper

\section{Introduction}

Unprecedented in respect of the scale and pace at which the reforms have been implemented (Annison et al., 2014), the full impact of the Transforming Rehabilitation (TR) "revolution", introduced into the probation service in England and Wales, is yet to become clear. Proponents argue TR widens the range of service providers, and so promotes innovation and efficiency, drives down costs and reduces recidivism (Ministry of Justice, 2013). Opponents, including many from the National Probation Service (NPS) and related staff associations, stress that the reforms would provide lucrative opportunities for private sector corporations to profit, via the Payment-by-Results (PBR) model, from working with low-risk clients but leave a much reduced public sector to deal only with high-risk offenders (Annison et al., 2014). Irrespective of viewpoint, however, commentators agree that TR is the most significant reform of the probation system since the introduction of the National Offender Management Service (NOMS) in (2003). McNeil (2013, p. 83) argued that TR "is really about disestablishing probation". This is true in organisational terms since the NPS lost much work to new Community Rehabilitation Companies (CRCs), but it does not necessarily follow that the management and supervision of offenders will be radically changed in terms of priorities, modalities and mentalities. As others have argued (Garland, 2003; Newburn, 2003), in focussing upon innovation, commentators often overlook the considerable continuity that characterises policy developments in the criminal justice sector.

Distinguishing between continuity and change, however, is challenging. To some extent, TR can be considered to significantly extend, rather than introduce the privatisation of the criminal justice sector (Annison et al., 2014). Twenty years ago, a study quoted a senior officer's observation that
Michael Rowe is a Professor of Criminology, Adele Irving is a Senior Lecturer in Criminology and Sarah Soppitt is the Head of Department, all at the Department of Social Sciences, Northumbria University, Newcastle upon Tyne, UK.

Received 26 July 2017

Revised 4 October 2017 Accepted 15 October 2017

(C) Michael Rowe, Adele Irving and Sarah Soppitt. Published in Safer Communities. Published by Emerald Publishing Limited. This article is published under the Creative Commons Attribution (CC BY 4.0) licence. Anyone may reproduce, distribute, translate and create derivative works of this article (for both commercial and non-commercial purposes), subject to full attribution to the original publication and authors. The full terms of this licence may be seen at http:// creativecommons.org/licences/by/ 4.0/legalcode

This study was funded by the Northumbria Probation Service and Safe Newcastle. 
"the Probation Service has absorbed the politics of punishment, entered the market place, mirrored the private sector [and] taken its managers through a grand renaming ceremony" (Wallis, 1997, cited in Garland, 2003, p. 177). While the earlier epoch of reform did not extend to wholesale privatisation, principles of private sector discipline in the form of New Public Management have been present for a considerable time (Paterson, 2007). In addition, many of the reforms instigated under TR offer the prospect of a greater role for third-sector agencies, and so reinvent historical arrangements whereby volunteers were engaged in offender rehabilitation (Mair and Burke, 2011, pp. 117-8). Other barriers to assessing the impact of TR can be identified from the public policy literature on implementation failure. Key among these is the "law of unintended consequences", where the outcomes of policy reform either fail to materialise as intended or transpire only partially or belatedly (Dunleavy and Hood, 1994). In public administration in general, and criminal justice policy-making specifically, there is a significant body of literature which suggests that caution should be exercised in predicting the impact of TR on the basis of a literal reading of the policy itself (Howlett, 2012; Boylan and Mocan, 2014; Ruggiero, 2010). The agency of organisations and personnel is likely to result in elements of the programme being resisted or ameliorated. Indeed, several studies examining the micro-contexts of probation practice doubt that the enforcement policy introduced through A New Choreography (National Probation Service for England and Wales and the Home Office, 2001) produced a culture of enforcement. Ugwudike (2016) found substantial deviation from official policies and guidance governing enforcement, which Robinson and Ugwudike (2012) suggested that "tough" enforcement policies suffered a legitimacy deficit at the frontline. Although TR might be detrimental to the status of officers (Robinson, 2013) and the capacity of staff to implement policy on their own terms might be reduced, professional discretion is likely to continue. This has been the experience in the practice of crime prevention and community safety more widely (Hughes, 2007). For these reasons, it is difficult to identify future directions in the organisation and philosophy of offender management and probation with a high degree of certainty.

To date, much of the debate and analysis surrounding TR has focussed on organisational restructuring, the professional culture of probation, the introduction of PBR and associated challenges such as the attribution of outcomes, the dynamic nature of risk and potential recidivism, and moral and ethical debates about private profit from punishment. However, the impact of TR on desistance - particularly from the perspectives of service users - has been largely neglected; this is despite Vaughan's (2007) argument that service users need to be understood as "active agents" within desistance programmes. Furthermore, as the concepts of effectiveness and compliance are "inextricably linked" (Bottoms, 2001, p. 89, cited in Robinson and McNeill, 2008), it is surprising that discussions of TR have neglected the impact of new models of supervision on this topic. To rectify this, this paper considers the impacts of service user-practitioner relationships and service user perceptions of the authenticity and legitimacy of offender management programmes, delivered both pre- and post-TR, to narratives of desistance. In doing so, it considers potential implications for wider debates about the current re-shaping of the criminal justice system. The paper will begin with a review of literature regarding the role of service user-practitioner relationships to perceptions of legitimacy, the nature of compliance and re-offending behaviour. Following this, a brief outline of the methodology of the study will be provided. Research findings are then used to analyse the potential implications of TR for compliance and desistance. This is done in terms of, first, the authenticity, instrumentality and legitimacy of relationships with practitioners and second, perceptions of various offender management programmes. Drawing upon McNeill and Robinson's (2013, p. 116) concept of "liquid legitimacy" - reflecting the ways in which legitimacy "changes its forms and shapes as a community sanction is negotiated, constructed, contested and reconstructed by the various actors and audiences involved" - it is argued that relationships between service users and supervisory officers seem not to be based upon perceptions of the sectoral status of programmes, but instead upon their philosophy, delivery style and perceived characteristic of staff. In that sense, the creation of a more diverse landscape under TR in terms of organisations involved in the delivery of desistance programmes - particularly third-sector organisations - might be beneficial for offender engagement and desistance. On the other hand, however, proposals to deliver offender management via remote technology such as satellites (Travis, 2016), kiosks or call centres, may preclude the development of positive relationships between service users and providers and so be detrimental to trust, authenticity and legitimacy, thus undermining desistance. 


\section{Service user-practitioner relationships, compliance and desistance}

The relationship between service users and staff remains the central mechanism for the delivery of community-based sanctions (Burnett and McNeill, 2005). Notwithstanding change and various paradigms of reform (McCulloch and McNeill, 2007), frontline staff have long maintained that legitimacy, authenticity, mutual understanding and collaboration are integral to effective relations and practice (Burnett and McNeill, 2005; McNeill, 2006, 2009). In a review of probation practice by Boswell et al. (1993, p. 148, cited in Burnett and McNeill, 2005, p. 223), officers identified "relationship making" as a key skill, and the authors concluded that casework had "come to be seen as a simple relationship-making process, which incorporated respect for the individual, rather than the somewhat obscure and esoteric practice of bygone years". Similar conclusions were made by Knott (2004, cited in Burnett and McNeill, 2005, p. 225), who, shortly before her appointment as the first NOMS Manager, emphasised the role of supervisor, not only as referrer and enforcer, but also motivator. Other senior practitioners have discussed the importance of case management in terms "relating to the offender" so that they feel "that somebody cares about them" (Mann, 2004, p. 44, cited in Burnett and McNeill, 2005, p. 225).

Desistance research into the effectiveness of interventions designed to reduce offending suggests that it is not so much the content of programmes or appropriateness of service users chosen to engage, but the service user-practitioner relationships surrounding these that are essential to reductions in re-offending. Evidence suggests that service users' commitment to desistance can be generated by the personal and professional commitment shown by their probation officers, with reasonableness, fairness and encouragement engendering a sense of personal loyalty and accountability. Advice about behaviours and underlying problems, interpreted by service users as evidence of concern for their wellbeing, can also acts a key source of motivation to change (Rex, 1999). However, it is only when relationships model virtues such as optimism, hopefulness, persistence, trustworthiness and loyalty that the formal authority of the probation officer is likely to be rendered legitimate in the mind of the offender (McNeill, 2006). The importance of perceptions of legitimacy can be explained by Bottoms' (2001) framework of compliance. He argued that authentic relationships are more likely to elicit normative compliance, based on a sense of moral obligation, a wish to maintain the alliance, and the perceived "legitimacy" of the conditions imposed.

The validity of this research is strengthened when looking at the impacts of enforcement-based relationships on levels of compliance and desistance. Enforcement-based policy and practice is founded on a model of offenders as rational actors, whose behaviour can be manipulated by incentives and disincentives. It is assumed that by informing offenders that non-compliant behaviour will be met with enforcement action, they will be more likely to desist (Robinson and Ugwudike, 2012). However, research indicates that offenders are relatively immune to the deterrent effects of formal sanctions (see e.g. Hearnden and Millie, 2004; Hedderman and Hough, 2004), with service users much less likely to comply for purely instrumental reasons and deterrent strategies most effective with those who have a stake in conformity (Bottoms, 2001). Robinson and Ugwudike (2012) found that studies exploring the links between "tough" enforcement and desistance have produced mixed findings. Although Home Office research tentatively indicates that taking appropriate enforcement action can increase desistance (May and Wadwell, 2001, cited in Robinson and Ugwudike, 2012, p. 305), other evidence suggests that "tough" enforcement can produce higher rates of reconviction (Hearnden and Millie, 2003, cited in Robinson and Ugwudike, 2012, p. 305). Indeed, research indicates that perceptions of rigidity and "regulatory unreasonableness" can alienate service users and increase (rather than reduce) the likelihood of future non-compliance (e.g. Sherman, 2003; Sherman et al., 2003; Digard, 2010; all cited in Robinson and Ugwudike, 2012, p. 305). When non-compliance is met with a response which is perceived as unjust or unfair, secondary non-compliance may follow (Lemert, 1967, cited in Robinson and Ugwudike, 2012, p. 305). For this reason, some scholars have warned that authorities seeking compliance should aim to protect their reputations as "legitimate" through fair and reasonable treatment (Murphy, 2005, cited in Robinson and Ugwudike, 2012, p. 305).

In exercising a note of caution, however, the extent to which service user-practitioner relationships are the most important factor in promoting desistance is subject to debate. Various studies into the offending patterns of young people suggest that their own resources and 
social networks, for example, are often better at resolving their difficulties than professional staff (Hill, 1999). The potential of wider social networks is highlighted by "resilience" or "strength-based" perspectives, which, in contrast to approaches that focus on risk and needs, consider the "protective factors and processes" involved in positive adaptation in spite of adversity. Such perspectives emphasise recognition, exploitation and development of offenders' competences, resources, skills and assets (Schoon and Bynner, 2003).

Building upon this body of literature, this paper considers the nature of legitimacy and service user perspectives on their relationships with staff. This is analysed in the context of a diverse range of programmes that (at least to some extent) reflect the more complex sector developing in the wake of the TR project. Prior to presenting findings and analysis, the next section of the paper outlines the methodology used in the data collection process.

\section{Methodology}

The data presented in this paper are derived from a series of semi-structured interviews with service users engaged in four different desistance programmes, delivered in one probation - now CRC - area in England. The interviews were carried out between 2012 and 2014 for evaluative studies commissioned by local community safety partnerships, a local charitable foundation and the probation service. One of the programmes was a voluntary scheme, delivered by a multi-agency team drawn from a range of criminal justice agencies. The second was a court-mandated scheme, whereby community penalties were delivered by a third-sector organisation contracted to the probation service. The third was also a community sentence delivered by the public sector, but by an individual employed (along with other skills and experience) on the basis that he/she had a personal history of crime and substance abuse. The fourth was a community sentence delivered by a private CRC, in conjunction with a network of local support agencies, which placed considerable emphasis on service users engaging in group work with their peers. It is recognised that the nature of the programme could impact upon a person's view of legitimacy: the analysis did not suggest significant or coherent differences between those from different schemes. Methodologically any differences would be difficult to attribute to the nature of that scheme since all had experiences of multiple interventions, and often couched their perceptions in broad terms drawing upon different episodes and engagement with a range of statutory and non-statutory agencies All of the programmes were multi-agency in nature and three of the four were delivered by a combination of public, private and third-sector groups, the other conducted by a combination of probation and police staff. The programmes were not selected for this analysis because they represented a range of types of provision but because each sought to deliver a form of integrated offender management, were delivered within the same region and were evaluated using a common methodology, which allows for a comparative discussion.

In total, interviews with 64 service users were carried out: 11 undertaking the first programme, 7 enroled in the second, 23 in the third and 23 in the fourth. Several service users were interviewed multiple times. The interviews were conducted in various locations and at different stages of service user engagement in the respective programmes. Spending time in the premises used by the programmes gave opportunities for informal fieldwork observations and unstructured discussion with staff and, occasionally, other service users present in reception areas or coffee rooms and some of this informs the discussion below. Naturally, the offending history of participants was varied, but the programmes were all targeted at those with relatively long-standing careers, comprised of low-gravity offending. All had multiple experiences of other sentences, both community-based and custodial, and with probation and other offender management programmes (delivered by youth justice agencies, for example). The majority of those interviewed were male: only 15 (23 per cent) were female; as such, the analysis offered below cannot address gendered differences. The interviews addressed a broad range of issues, including respondents' offending histories, previous engagements with the criminal justice system, perspectives on desistance and "lifestyle normalisation" and attitudes towards staff delivering their current programme. Interviews took place in private spaces in the various premises where the services were provided and typically lasted between 20 and 40 minutes. They were fully transcribed and thematically analysed. The study was approved by the research team's university ethics committee. 


\section{Research findings}

An important finding from the studies is that service user perceptions of their motivation to desist from crime were often expressed in terms of their relationship with support workers. In circumstances where service users reported positive relationships, these tended to be cited as a reason for a strong commitment to desistance. It is shown below that there were three important components to a positive relationship: authenticity, instrumentality and programme ethos. Each of these is analysed below and the implications that each might have in terms of key elements of the TR agenda are considered.

\section{Authenticity}

Service users frequently expressed that their strong commitment to desistance was derived from the perceived authenticity of the staff with whom they were working. Each of the programmes was designed such that service users would develop a close working relationship with an individual practitioner - whether this be a qualified practitioner or a peer mentor. Positive assessment of those was predicated either on the basis that the staff members were "authentic" in terms of their personal biography or that they had a genuine and demonstrable commitment to supporting the service user. As noted above, the third of the four programmes was largely facilitated by an individual employed to work as a peer mentor with service users. The individual had an extended history of offending and substance abuse. Not only was this individual respected by many of those interviewed on the basis of successfully managing their personal desistance, credibility was also given since that person was continuing in their "recovery journey" through further support from other peer mentors. Three extracts from service user interviews reflect these perceptions:

He's singing the right notes [...] He's been there and done it. He's in a good place now [...] l've seen where he was, he was in a bad place and now he's in a good place [...] and that's where I want to be (Project 3, Respondent 1).

He's been through it. You've got to have been through it. It's hard to explain it. That's why it's good that they have people like him working in these sorts of places. You feel better talking to them (Project 3, Respondent 2).

It takes an addict to understand another addict [...] most everyday people will never, ever get it [...] only an addict understands (Project 3, Respondent 3).

The "understanding" mentioned by Respondent 3 did not mean, necessarily, that service users found this engagement more palatable or in some way easier to negotiate. Indeed, the relationship could be challenging, as noted in fieldwork observations when service users were questioned in terms of their presentation of the inevitability of their drug use or their inability to sustain abstinence. Even so, service users valued that the peer mentor had personal experience that made for a more honest - or more authentic - relationship. One interviewee noted that:

It doesn't matter how much you relapse or what mistakes you have made, that support will always be there, they won't judge you, you won't get in trouble from being honest with them. There's no pressure [...] I can just focus on myself (Project 3, Respondent 4).

As is noted in more detail further below, this authenticity was often positively contrasted with respondent's previous experiences of offender management programmes. While the extract below is from a service user engaged in the third project, similar points were made by interviewees involved in the fourth project, which also involved an element of group work with peers. The interview extracts below indicate the value placed on engagement with peers with credible personal experience, and that this was assessed as more significant than working with those more formally qualified:

It's quite good to be involved with people in similar situations, I can sit and talk about my problems to professionals and they just sit there and nod and they don't understand at all. Where you can sit and talk to a complete stranger who's been through similar experiences and even though they might not have these qualifications, these people who are lower down the qualification level, understand a lot more. It's like a breath of fresh air (Project 3, Respondent 1). 
I liked it really, I spoke to everybody, people listened to you and everybody had been through the same type of stuff. I knew the man (the mentor), l'd know him from years before, I felt comfortable with him.

They were all spot on (Project 4, Respondent 1).

In terms of engaging a broader range of voluntary third-sector organisations in a post-TR landscape, this is significant. The broader literature around peer mentoring has noted the value that authenticity offers, but that this can be in tension with the professional expertise of trained and qualified staff. Vennard and Hedderman (2009) argued that the perceived value of voluntary sector input into desistance programmes stemmed from the distinct tradition of working outside the framework of offender management, but that this risked being undermined as third-sector organisations become further enmeshed into contractual relations with criminal justice agencies. TR has significantly accelerated this development since third-sector, social enterprise and community interest companies are contractual partners in all of the 21 probation areas (Annison et al., 2014).

Another component of the authenticity of staff valued by interviewees was the perceived strength of their commitment to assisting service users. Furthermore, in terms of transforming ex-offenders' social identity, the positive experience of demonstrable commitment from staff was understood as evidence that the service user had some value not previously recognised. Content wise, these desistance programmes were underpinned by "strengths-based" approaches, which encouraged service users to develop social capital and imagine themselves in terms not solely defined by anti-social, problematic and criminal behaviour (McNeill, 2006). The authenticity underpinning this perception was based on the congruence between content, communication and demonstrated staff behaviour. This perspective was encapsulated in the comments of Respondent 1 in Project 2. She reflected on an experience whereby staff from the project had attended a ceremony to mark completion of the scheme:

[...] they are more hands on, on the other end of the phone [...] picking us up and things like that, if I was short of bus fare. It's a close bond that you have with them [...]. They are all lovely [...] all really nice. The [project name] had like a passing-out thing. I didn't know that you could have people there, all the other lads have carers and family there, I was the last to get up and talk and when I sat down someone told me that [names staff]were there at the back. I thought "e, my God!", I was buzzing and that, they'd come to see us! I was chuffed to bits, that was really nice (Project 2, Respondent 1).

In sum, the perceived authenticity of staff was typically associated either with their professional commitment to service users and/or their personal experience of offending and desistance. The latter element related to the notion of offender biography and the concept of narration of a pro-social identity, whereby desistance emerges from socio-psychological recalibration of the offenders perceived relationship with their external environment, social relationships and future potential (Farrall, 2002). A key feature of the TR agenda is to establish a more diverse set of service providers, with the greater engagement of the voluntary sector in the delivery of desistance appearing particularly likely. Our data suggest that a more mixed economy of provision - including the greater involvement of peer mentors and volunteers - might be beneficial if those engaged are regarded as authentic in their commitment to their work.

\section{Instrumentality}

The discussion above demonstrates that the legitimacy of desistance programmes was partially constructed in terms of the social identity of the service users and their perceptions of relationships with staff. Accompanying this was the perception that service users benefitted from engagement in the programme in instrumental ways. The nature of the instrumental returns ranged from mundane day-to-day support, to more substantive benefits relating to lifestyle normalisation, for example. Participants in Project 3 spoke positively in interviews about the ease and effectiveness of engaging with staff, with responses including: "everything has been spot on since I've met him", "If you ever ask him to do anything, he's straight there. The support you get from him is second to none", "He's done more than he's paid to do", "He's always there, he's committed". Across all the programmes, respondents valued assistance aimed at helping them to organise "chaotic lifestyles". Sometimes this was expressed in respect of routine activities, such as calling to remind of forthcoming appointments and to provide transport to attend, or simply to check on their wellbeing. Similarly valued was advice to service users in relation to 
accessing a wider range of support services to provide help in terms of recovery, health and fitness, housing and benefits (including avoiding potential benefit sanctions), meaningful activities and education, training and employment. One respondent expressed the instrumental benefits, and the importance of that to maintaining desistance, in the following terms:

[Staff name] would come and see [me to] ask how I was doing; if I needed any help. He took me to [agencies] [...] I got registered with Crisis. I did the Health and Hygiene course. Just introduced me to some people that would help me with, like, my CV; getting into jobs and all that [...] if [staff name] never came to see me in prison or I never became involved here at the [programme], I'd probably be either in prison or due to go into prison or sitting with a drug habit and reoffending (Project 1, Respondent 1).

Similarly, a respondent in the fourth programme noted practical benefits in terms of facilitating wider support networks and that this was combined with developing their personal capacity within these environments:

I get support from [staff name] if I need it: like [agency name], [agency name], [agency name]. She's got me to understand that I don't have to accept what's offered, I can change what's on offer. I find it hard to open up in a group, or to open up in a group. But in the future I could come back and have a word with [staff name], I know she'd be there for that (Project 4, Respondent 3).

These extracts suggest that positive evaluations of programmes were partially predicated on resulting instrumental benefits, but that these were often couched in relatively minor terms and only indirectly associated with desistance. This is significant in terms of the wider intention of TR to introduce PBR mechanisms, since service users assessed some relatively minor outcomes as being especially significant as potential pre-requisites or indeed, integral to sustained desistance. The value attributed to these minor outcomes indicates that the legitimacy of the programme was based, in part, on service users engaging more firmly within networks of local support agencies. This in turn means that there might not be an overall reduction in referrals to local multi-agency networks, and so evaluations using methodologies such as Social Return on Investment models (SROI Network UK, 2011) need to become sufficiently sophisticated to identify costs that enhance long-term desistance. Another challenge is that for such work to prove beneficial in the long term, there is an inherent need for local networks to exist in the first instance. Current pressures on public sector provisions will make this more challenging and perhaps the fluidity and instability of these local networks will mean that supporting service users to negotiate a shifting landscape of providers is increasingly important. If the metaphor of desistance as a journey is extended, then the route map requires frequent updates from an expert navigator.

Service users often valued the capacity of staff to help them to identify a positive conception of their future self and to begin to narrate a new social identity. Frequently this was articulated in terms of improving relations with friends and family. The quote below from a service user illustrates the instrumental impact that engagement with the programme was held to offer in these terms. It further demonstrates that benefits which might accrue from the desistance programme can be understood in narrow terms of crime reduction, but actually are considered more broadly by service users. Attributing and measuring such outcomes for the purposes of PBR would be extraordinarily challenging:

[...] society has changed now, people don't buy stolen goods now, they know it is a crime. A lot of people who used to steal don't now, they've got jobs, the people I used to hang around with have got themselves into college courses, they have got jobs and settled down with families. They've managed to stick in their jobs, and that has changed people's perceptions about crime. My sons know now not to commit crime, and that if they do they'll get into trouble for it. When I was younger, when I was committing crime, I was applauded for it. It's different for my sons, they won't be appreciated for it. They know not to go to the shops if they've got no money (Project 2, Respondent 2).

This section has shown that the (real or perceived) instrumental benefits that staff could provide in terms of negotiating with other service providers, benefits agencies, housing providers and the like were often central to positive evaluations of engaging with desistance programmes. Our research found that these benefits related secondarily to desistance and were couched in broader terms of assisting with "lifestyle normalisation". Support to access and engage with a range of agencies is widely recognised as a vital precursor to desistance (LeBel et al., 2008; McNeill, 2006, 2009), and our findings support this. However, identifying the impact of such "soft outcomes" and then attributing payment for that result is challenging (Vennard and Hedderman, 2009). 


\section{Sectoral status and programme ethos}

A central element of the TR reforms has been the development of a more diverse range of providers of offender management. All 21 of the contracts that established the new CRCs were awarded to consortia comprising public, private and third-sector organisations. These included multinational corporations, public agencies including NHS trusts, charities (both national and local), not-for-profit social enterprise companies and community interest companies (some of which were constituted by former probation officers). While the development of multi-agency and cross-sectoral delivery is not new within criminal justice, this aspect of TR has been a major step in a wider process of privatisation (Annison et al., 2014). As noted above, this has been subject to extensive critical analysis, for which there is no room to rehearse here (Burke and Collett, 2016; Dominey, 2016; Harper, 2013; McNeil, 2013). But notably, little of this has drawn upon the insights of service users and so the analysis offered below adds further perspectives on these wider debates.

In various combinations, the four programmes from which research respondents were drawn were delivered in a multi-agency environment. Project 1 was delivered under contract by a charity that had little prior history in criminal justice. Service users reported that the charitable status of the project, and its independence from the CJS, enhanced the trust and confidence that were significant factors in their motivation to desist. The legitimacy of the programme was often expressed in terms of how it positively differed from service users' previous engagement with probation services. The interview extracts below illustrate the widely expressed perception that the programme was valued partly because of the contrast with prior engagements:

When I had probation in the past, I just walked into a room, they asked a couple of questions and that was it. That was basically it: you've showed your face, you can go now. Not "How you doing? Are you keeping out of trouble?" nothing like that. [This programme] is different [...]. It's much better. They seem to care for you, they ask how you're doing, whereas I have never had none of that [...] (Project 1, Service User 2).

Probation is more like a school isn't it, if you are late, they just breach you then, there is no leeway, where here it's more easy going, everyone's ok really, it's alright [...] They treat you like an adult, not like a kid (Project 1, Service User 3).

Service users were clearly aware that the project was being delivered by a charity (not least since it was run from their premises) and often articulated that there was an ethos distinct from previous engagements, and this enhanced perceived legitimacy of the programme. While this suggests that the sectoral status of the delivering organisation underpins service users' perceptions of legitimacy and motivation towards desistance, the picture becomes more complex when considering the interviews with service users engaged in projects delivered by other configurations of agencies. Those engaged in Project 2 also expressed their positive perceptions by contrasting their experience with less positive prior offender management. Project 2 was entirely delivered by public service organisations (a combination of probation service staff and police). The extract below shows how service users contrasted the experience of that project with mainstream probation:

It's not, like, "how have you been doing [...] Blah-di-blah", like five minutes and you're out of here. But they, like, have the time to talk to you and stuff like that, do you know what I mean? Like, ask how you've been doing and things like that. It's just better, rather than coming in and just, do you know what I mean, doing nothing? (Project 2, Service User 3).

The peer-mentoring component of the third project and the strengths-based approach to delivering the fourth project were similarly recognised by service users as distinguishing characteristics that contrasted positively with previous offender management. From whatever sector, or combination of sectors, the project was being delivered, service users perceived legitimacy in terms of relations with staff and that this was contrasted with the perceived normal pattern of probation work. In sectoral terms, legitimacy was "liquid" in the sense that it seeped around boundaries between public, private and third sectors. While legitimacy might be articulated in terms of the ethos of a charitable organisation, the service user interviews suggested that this perception could be morphed and expressed in similar terms to programmes delivered by public and private sector agencies. In terms of the ambition of TR to diversify service 
provisions by including private and not-for-profit organisations, this suggests that such developments might enhance legitimacy among service users, but only in circumstances where an ethos is embedded that prioritises authentic relationships of the type outlined in the earlier section of this paper. Conversely, it follows, legitimacy will be harder to sustain where such relationships are absent; discussion of the possibility of introducing electronic monitoring of low-risk offenders or of delivering supervision remotely via kiosks at which service users check-in effectively excludes the possibility of authentic relationships and so seem likely to have deleterious effects in terms of legitimacy and desistance.

In sum, the identity and ethos of programmes and their relation to offender perspectives on desistance appeared significant. Indeed, it is timely to consider how service users perceive the status of organisations with which they engage in light of the diversified landscape of delivery organisations under TR. Our research findings suggest that service users were relatively unconcerned with the formal sectoral status of the delivery organisation(s). What emerged from the interview data, however, was a strong value placed on the programme being distinctive from the usual experience of offender management services. From where this distinctiveness was delivered was less important than that the programmes were understood by those engaged in them as being out with the usual parameters and ethos (real or perceived) of mainstream provision. This has two potential ramifications in a post-TR environment characterised by multi-sectoral and multi-agency provisions. Positively, that greater perceived legitimacy may result in increased engagement under TR. More concerning, however, is that proposed electronic or remote monitoring without sustained relations with staff post-TR may be detrimental to engagement and desistance.

\section{Conclusion}

The primary intention of this paper has been to consider the importance of relationship-based practice in current probation interventions aimed at reducing re-offending and to use these findings to provide insight into the impacts that various elements of TR might have on service user perspectives of the legitimacy of programmes delivered in a more diverse sectoral environment. The data add perspectives from service users that have tended to be marginalised in wider debates about changes to probation and offender management in England and Wales. Three key themes emerge. First, positive perceptions of the legitimacy of staff and programmes had no relation to their formal status in sectoral terms. Instead, service users valued the authenticity of staff in terms of their personal commitment to assist them; sometimes this was related to their personal biographical experience of crime and substance abuse. If TR succeeds in establishing an environment for offender management in which a wide range of third, private and public sector agencies contribute to desistance programmes, it might be that this proves an effective way of enhancing legitimacy in the eyes of service users. However, the value that personal credentials offer in terms of staff and programme authenticity maybe in tension with a counter-veiling tendency towards the development of evidence-based practice within probation. The interviews reported above suggest that service users value authenticity and sometimes express this via a negative comparison with remote "professional" experts with whom they lack rapport. While it might be possible to reconcile professional expertise and personal authenticity, this paper suggests that this will be a continuing challenge. Related to this is the risk that as third-sector organisations become further enmeshed in contractual relations with private and public criminal justice providers, the distinctive tradition of voluntarism is eroded. TR risks undermining the values that service users identify as central to the legitimacy of those working outside of public sector mainstream offender management.

A second theme emerging from the discussion above relates to the difficulty of ensuring effective mechanisms for PBR. These challenges have been noted elsewhere (Fox and Albertson, 2011), but service user interview data reported here suggest that the instrumental outcomes that service users valued were often only indirectly related to desistance and often appeared to be relatively minor in themselves. They were the "soft outcomes" identified previously by Vennard and Hedderman (2009). These benefits might have contributed in various ways to "lifestyle normalisation", but only at a distance were they linked to reduced offending and so might be removed from the formal outcomes that trigger payments. Equally problematic for PBR is that the outcomes that do relate to desistance are subject to a delay since they are secondary to more immediate steps such as referral to welfare or health services. The temporal lag means that 
the secondary outcome (desistance) is not understood by PBR mechanisms as a result that stemmed from the primary outcome (agency referral, or similar).

A third theme arising from the data is that the sectoral status of desistance programmes did not seem to determine the legitimacy perceived by service users. What was highly significant was that the ethos, values and culture of programmes were outside of the normal experience of probation and offender management. Staff and programmes that prioritised the building of meaningful relationships with service users were valued highly, and this was often expressed as a positive contrast with other experiences with shallow or cursory interaction with staff. In terms of the TR agenda, this might suggest that innovative programmes delivered by different combinations of service providers have the potential to achieve greater levels of legitimacy. Counter to this are components of TR that prioritise greater efficiencies in terms of community supervision of low-risk offenders. If providers, whether public, private or voluntary, develop - as has been widely mooted - systems that remotely monitor service users using electronic tagging or through check-in kiosks, then the personal relationships valued highly by service users will be disappear and the legitimacy arising from those relations will be greatly eroded. The perspectives of service users on those forms of monitoring would form a useful avenue for future research. Moreover, further studies addressing themes outlined in this paper in other $\mathrm{CRC/probation} \mathrm{eras} \mathrm{would} \mathrm{be} \mathrm{a}$ valuable way of testing the findings outlined. What is more, to do this over an extended time period during which service user recollections of "pre-TR" provisions might fade would test the importance of comparing diverse post-TR services with what went before.

\section{References}

Annison, J., Burke, L. and Senior, P. (2014), "Transforming Rehabilitation: another example of English 'exceptionalism' or a blueprint for the rest of Europe?”, European Journal of Probation, Vol. 6 No. 1, pp. 6-23.

Boswell, G., Davies, M. and Wright, A. (1993), Contemporary Probation Practice, Avebury, Aldershot.

Bottoms, A. (2001), "Compliance and community penalties", in Bottoms, A., Gelsthorpe, L. and Rex, S. (Eds), Community Penalties: Changes and Challenges, Willan, Cullompton, pp. 87-116.

Boylan, R.T. and Mocan, N. (2014), "Intended and unintended consequences of prison reform", Journal of Law, Economics and Organization, Vol. 30 No. 3, pp. 558-86.

Burke, L. and Collett, S. (2016), "Transforming Rehabilitation: organizational bifurcation and the end of probation as we knew it?", Probation Journal, Vol. 63 No. 2, pp. 120-35.

Burnett, R. and McNeill, F. (2005), "The place of the officer-offender relationship", Probation Journal, Vol. 52 No. 3, pp. 221-42.

Digard, L. (2010), "When legitimacy is denied: sex offenders' perceptions and experiences of prison recall”, Probation Journal, Vol. 57 No. 1, pp. 1-19.

Dominey, J. (2016), "Fragmenting probation: recommendations from research", Probation Journal, Vol. 63 No. 2, pp. 136-43.

Dunleavy, P. and Hood, C. (1994), "From old public administration to new public management”, Public Money and Management, Vol. 14 No. 3, pp. 9-16.

Farrall, S. (2002), Rethinking What Works with Offenders: Probation, Social Context and Desistance from Crime, Willan Publishing, Cullompton.

Fox, C. and Albertson, K. (2011), "Payment by results and social impact bonds in the criminal justice sector: new challenges for the concept of evidence-based policy?", Criminology and Criminal Justice, Vol. 11 No. 5 , pp. 395-413.

Garland, D. (2003), The Culture of Control: Crime and Social Order in Contemporary Society, Oxford University Press, Oxford.

Harper, C. (2013), "Transforming Rehabilitation and the creeping marketisation of British public services", British Journal of Community Justice, Vol. 11 Nos 2/3, pp. 37-43.

Hearnden, I. and Millie, A. (2004), "Does tougher enforcement lead to lower reconviction?", Probation Journal, Vol. 51 No. 1, pp. 48-58. 
Hedderman, C. and Hough, M. (2004), "Getting tough or being effective: what matters?", in Mair, G. (Ed.), What Matters in Probation, Willan Publishing, Cullompton, pp. 146-69.

Hill, M. (1999), “Accentuating the positive: resilience and desistance approaches to children's needs and behaviour", in Hill, M. (Ed.), Children's Services: Working Together, Routledge, London, pp. 234-46.

Howlett, M. (2012), "The lessons of failure: learning and blame avoidance in public policy-making", International Political Science Review, Vol. 33 No. 5, pp. 539-55.

Hughes, G. (2007), The Politics of Crime and Community, Palgrave, London.

LeBel, T.P., Burnett, R., Maruna, S. and Bushway, S (2008), "The 'chicken and egg' of subjective and social factors in desistance from crime”, European Journal of Criminology, Vol. 5 No. 2, pp. 131-59.

Lemert, E.M. (1967), Human Deviance, Social Problems and Social Control, Prentice Hall, Englewood Cliffs, NJ.

McCulloch, T. and McNeill, F. (2007), "Consumer society, commodification and offender management", Criminology and Criminal Justice, Vol. 7 No. 3, pp. 223-42.

McNeil, F. (2013), "Transforming Rehabilitation: evidence, values and ideology", British Journal of Community Justice, Vol. 11 Nos 2/3, pp. 83-5.

McNeill, F. (2006), "A desistance paradigm for offender management", Criminology and Criminal Justice, Vol. 6 No. 1, pp. 39-62.

McNeill, F. (2009), "What works and what's just?", European Journal of Probation, Vol. 1 No. 1, pp. 21-40.

McNeill, F. and Robinson, G. (2013), "Liquid legitimacy and community sanctions", in Crawford, A. and Hucklesby, A. (Eds), Legitimacy and compliance in criminal justice, Willan, Cullompton, pp. 16-137.

Mair, G. and Burke, L. (2011), Redemption, Rehabilitation and Risk Management: A History of Probation, Routledge, New York, NY.

Mann, S. (2004), “'Effective implementation' in management of evidence-based practice in probation”, Proceedings of a Conference held by Conférence Permanente Européenne de la Probation and the National Probation Service for England and Wales, Oxford, 3-5 March.

May, C. and Wadwell, J. (2001), "Enforcing community penalties: the relationship between enforcement and reconviction", 155, Home Office Research Findings, Home Office, London.

Ministry of Justice (2013), Transforming Justice: A Revolution in the Way We Manage Offenders, Stationary Office, London.

Murphy, K. (2005), "Regulating more effectively: the relationship between procedural justice, legitimacy and tax non-compliance", Journal of Law and Society, Vol. 32 No. 4, pp. 562-89.

National Probation Service for England and Wales and the Home Office (2001), "A new choreography: An integrated strategy for the national probation service for England and Wales", Strategic Framework 20012004, Home Office, London.

Newburn, T. (2003), Crime and Criminal Justice Policy, Longman, London.

Paterson, C. (2007), "Commercial crime control and the electronic monitoring of offenders in England and Wales", Social Justice, Vol. 34 Nos 3/4, pp. 98-110.

Rex, S. (1999), "Desistance from offending: experiences of probation", Howard Journal of Criminal Justice, Vol. 38 No. 4, pp. 366-83.

Robinson, A. (2013), "Transforming Rehabilitation: transforming the occupational identity of probation workers?", British Journal of Community Justice, Vol. 11 Nos 2/3, pp. 91-101.

Robinson, G. and McNeill, F. (2008), "Exploring the dynamics of compliance with community penalties", Theoretical Criminology, Vol. 12 No. 4, pp. 431-49.

Robinson, G. and Ugwudike, P. (2012), "Investing in 'toughness': probation, enforcement and legitimacy", The Howard Journal of Crime and Justice, Vol. 51 No. 3, pp. 300-16.

Ruggiero, V. (2010), "Unintended consequences: changes in organised drug supply in the UK", Trends in Organized Crime, Vol. 13 No. 1, pp. 46-59. 
Schoon, I. and Bynner, J. (2003), "Risk and resilience in the life course: implications for interventions and social policies”, Journal of Youth Studies, Vol. 6 No. 1, pp. 21-31.

Sherman, L. (2003), "Defiance, deterrence and irrelevance: a theory of the criminal sanction", Journal of Research in Crime and Delinquency, Vol. 30 No. 4, pp. 445-73.

Sherman, L., Strang, H. and Woods, D. (2003), "Captains of restorative justice: experience, legitimacy and recidivism by type of offence", in Weitkamp, E. and Kerner, H. (Eds), Restorative Justice in Context: International Practice and Directions, Willan, Cullompton, pp. 229-56.

SROI Network UK (2011), What is Social Return on Investment?, SROI Network, London.

Travis, A. (2016), "Satellite-tracking schemes for offenders to be trialled this autumn", The Guardian, 8 July, available at: www.theguardian.com/uk-news/2016/jul/08/satellite-tracking-schemes-for-offenders-to-betrialled-this-autumn?CMP=share_btn_link (accessed 15 July 2016).

Ugwudike, P. (2016), "The dynamics of service user participation and compliance in community justice settings", Howard Journal of Crime and Justice, Vol. 55 No. 4, pp. 455-77.

Vaughan, B. (2007), "The internal narrative of desistance", British Journal of Criminology, Vol. 47 No. 3, pp. 390-404.

Vennard, J. and Hedderman, C. (2009), "Helping offenders into employment: how far is voluntary sector expertise valued in a contracting-out environment?", Criminology and Criminal Justice, Vol. 9 No. 2, pp. 225-45.

Wallis, E. (1997), "A new choreography: breaking away from the elaborate corporate dance", in Burnett, R. (Ed.), The Probation Service: Responding to Change, Probation Studies Unit, Oxford University, Oxford, pp. 91-104.

\section{Further reading}

Brown, M. and Stuart, R. (2010), "Mentoring, social capital and desistance: a study of women released from prison", Australian and New Zealand Journal of Criminology, Vol. 43 No. 1, pp. 31-50.

\section{Corresponding author}

Michael Rowe can be contacted at: michael.rowe@northumbria.ac.uk 